\title{
NATAL AND NEONATAL TEETH
}

\author{
Ana Lucía Seminario, Romana Ivančaková \\ Charles University in Prague, Faculty of Medicine in Hradec Králové, Czech Republic: Department of Dentistry
}

Summary: Tooth eruption follows a chronology corresponding to the date when the tooth erupts into the oral cavity. This date has been established in the literature and is subject to small variations depending on hereditary, endocrine and environmental features. Any disturbance during the development of the teeth -systemic or local- can affect not only the morphology, structure of dental hard tissues or number of teeth but also the time of eruption. The presence of a tooth in the mouth at birth or during the first month of life has been studied and denominated as natal and neonatal teeth. The aim of this paper is to review current information on this topic and to give treatment alternatives if it is necessary.

Key words: Natal and neonatal teeth; Supernumerary teeth; Riga-Fede disease

\section{Introduction}

The success in the diagnosis, treatment and clinical procedures in dentistry involves good knowledge of dental structures morphology and the dynamics of growing and development of the dentition. Child development from conception through the first year of life is marked by many changes. Tooth eruption at about 6 months of age is a milestone both in terms of functional and psychological changes in the child's life and in emotional terms for the parents.

The expectations about the eruption of the first teeth are great and even greater when the teeth appear early in the oral cavity. When teeth are observed at birth or during the first month of life, being denoted natal and neonatal teeth, respectively, the interest, curiosity and concern of clinicians are similar to that of the parents.

Because of its rare occurrence, in the past this anomaly of eruption was associated with folklore, superstition, being related to good or bad omens. This explains the many reports about this topic since 59 B.C., as observed in cuneiform inscriptions detected in the $19^{\text {th }}$ century.

Today, these teeth also stimulate the interest of both parents and health professionals because of their clinical characteristics, among them their great mobility, which raises concern about the possibility of their being swallowed or aspirated by the infant during nursing. The objective of the study was to present a review of the literature and clinical management techniques for natal and neonatal teeth.

\section{Definition}

Several terms have been used in the literature to designate teeth erupting before the normal time, such as con- genital teeth, fetal teeth, predecidual teeth and dentitio praecox. According to the definition presented by Massler and Savara (1950) (36), taking only the time of eruption as preference, natal teeth are those observable in the oral cavity at birth and neonatal teeth are those that erupt during the first 30 days of life. This definition has been accepted and used by most authors.

\section{History}

The presence of natal and neonatal teeth has been reported and associated with interesting beliefs during time. The first reports came from Roman times with Titus Livius (59 BC) and Caius Plinius Secundus (23 BC) (23). The first considered the presence of natal teeth to be a prediction of disasterous events while the second believed that a splendid future awaited male infants with natal teeth, whereas the same phenomenon was bad omen for girls. In many African tribes children born with teeth were murdered soon after birth because they were believed they bring misfortune to all they would contact.

In England, the belief was that babies born with teeth would grow to be famous soldiers whereas in France and Italy the belief was that this condition would guarantee the conquest of the world. Historical figures such as Hannibal, Luis XIV, Mazarin, Richelieu, Richard II and Napoleon may also have been favoured by the presence of natal teeth $(2,23,36)$.

\section{Prevalence}

Massler and Savara (36) reported a frequency of 1:2000 birth, $95 \%$ of them were deciduous teeth and only $5 \%$ su- 
pernumerary. The literature reports incidence goes from 1:2000 to 1:3500 births (4). Kates, Needleman and Holmes (29) made a study with 18,155 infants and showed a prevalence of 1:716 live births. Leung (34) evaluated 50,892 infants over 17 years and found a prevalence of 1:3392 natal teeth. Even when there is not established (20), some investigators as Kates et al. (29) reported a higher prevalence of natal teeth in females with $66 \%$. The variation in prevalence depends on the different population studied and on the methods employed in each study.

\section{Aetiology}

Many theories have been reported in order to explain the etiology of this phenomenon. The presence of natal and neonatal teeth is definitely a disturbance of histological chronology whose aetiology is still unknown. Some investigators suggest that natal teeth may be associated with some syndromes such as Ellis-van Creveld (Chondroectodermal dysplasia) (16,26), Hallerman-Streif (17), Pachyonychia congenita $(13,45)$, Wiedemann-Rautenstrauch (51), cleft palate and cleft lip $(16,21)$ and Soto (9).

It has been assumed that early eruption of primary teeth is the result of abnormal position of the germ during its development in the alveolar bone $(5,40)$. Stewart and Prescott (50) believed that the superficial position of the dental germ increased rate of eruption due to febrile incidents, hormonal stimulation and heredity. Hals (22) thought that natal teeth were the result of hereditary influences. Bodentoff and Gorlin reported a family association in $14.5 \%$ of cases whereas Kates, Needleman and Holmes (29) found a positive family history in 7 of 38 cases of natal and neonatal teeth.

Osteoblastic activity has also been reported as a possible factor of this anomaly. Clergueau-Guerithault (26) suggested that the eruption of natal and neonatal teeth could be dependent on osteoblastic activity within the area of the tooth germ.

\section{Clinical characteristics}

Most of natal and neonatal teeth reported are early erupted teeth of normal deciduous dentition. The prevalence of supernumerary teeth has been suggested as ranging from 1 to 10\% (29). Rusmah (43) described natal and neonatal teeth as conical or normal in size and shape and opaque yellow-brownish in colour. Bigeard (9) reported that dimensions of the crown are smaller than those reported by Lautrou (32) for primary teeth under normal conditions.

Histological reports about natal and neonatal teeth have shown that despite the normal structure of enamel of these teeth, early eruption interrupts the mineralization process of enamel $(6,22)$. Hence, enamel has often been described as dysplastic or hypomineralized and has a tendency to wear and discolour (10).
Soni et al. (47) have published a microradiographical and polarized light microscopy (PLM) study of natal and neonatal teeth. They found enamel hypoplasia and dentinal disturbances including formation of irregular dentin and osteodentin in the cervical portions and interglobular dentin in the coronal region.

Meryem et al. (38) evaluated the surface topography of mandibular natal and neonatal incisors at the ultrastructural level using the scanning electron microscope (SEM). They found the hypoplastic enamel, depressed areas and the incisal edge of natal tooth lacked of enamel. In addition, root formation of the teeth was not complete which correlated with findings that teeth may erupt without root formation.

There is an interesting histological report on an upper natal molar made by Friend (18). He demonstrated that the alteration in amelogenesis detected in this tooth was due to premature exposure of it to the oral cavity, which finally resulted in metaplastic alteration of the epithelium of the normally columnar enamel to a stratified squamous configuration. This squamous aspect of enamel was visualized in the study made by Biggeard et al. (9).

The terms natal and neonatal teeth proposed by Massler and Savara (36) were limited only to the time of eruption, they did not consider the anatomical, morphological or structural characteristics of the teeth. Spouge and Feasby (49) in 1966 proposed a classification of these teeth based on their clinical characteristics. These teeth were then classified into:

Mature - when they are fully developed in shape and comparable in morphology to the deciduous teeth.

Immature - when their structure and development are incomplete.

The term mature may suggest that the tooth is well-developed compared to the remainder of the primary dentition and that its prognosis is relatively good. In contrast, the term immature assumes the presence of an incomplete structure and implies a worse prognosis for the tooth in question. On the basis of the literary data, Hebling (1977) (24), recently classified natal teeth into 4 clinical categories:

1. Shell-shaped crown poorly fixed to the alveolus by gingival tissue and absence of a root.

2. Solid crown poorly fixed to the alveolus by gingival tissue and little or no root.

3. Eruption of the incisal margin of the crown through gingival tissue.

4. Edema of gingival tissue with an unerupted but palpable tooth.

\section{Diagnosis}

It is important to determine if the tooth belongs to normal deciduous dentition or if it is supernumerary. Most of natal and neonatal teeth are primary teeth of the normal dentition and not supernumerary teeth (14). The use of cli- 
nical and radiographic methods has been suggested by many authors $(8,34,43)$. Radiographic verification shows adjacent structures of tooth and the presence or absence of germ in the primary tooth area (3).

Natal and neonatal teeth are usually located in the region of the lower incisors and are duplicated in $61 \%(2,11,29)$. Multiple natal teeth are extremely rare (41). However, some authors reported a case of natal teeth in which a second upper molar and lower canine were involved (37,52). Cysts of the dental lamina and Bohn nodules may be confused with neonatal teeth, the diagnosis can be made by radiographic examination $(28,41,55)$.

Diagnosis is important for the maintenance of natal and neonatal teeth of the normal dentition. Premature loss of a primary tooth causes a loss of space and collapse of the developing mandibular arch with consequent malocclusion in permanent dentition (31).

\section{Treatment and complications}

The management of natal teeth depends on many factors. If it is a supernumerary tooth, then extraction is the best choice of treatment. If the tooth is excessively mobile and has poor implantation it is better to extract it and avoid risk of deglution or inhalation. Hooley (25) found that $67 \%$ of natal and neonatal teeth would exfoliate prematurely, due to inadequate root formation and mobility of these teeth in the mouth. Bjueggren (10) published a report of 121 cases; he found that $38 \%$ of the natal and neonatal teeth exfoliated in the first year of life. When extraction is decided, it is necessary to be sure that the underlying dental papilla and Hertwig 's epithelial root sheath are removed by a gentle curettage, otherwise, root development with continued (15). Ryba, Kramer, and Southam $(44,48)$ reported that if there is remaining dental papilla, with the persistence of part of the radicular epithelial sheath of Hertwig there is a possibility of continuous dentin formation.

Extraction of these teeth is usually a simple procedure. But, it is important to recall precautions when the infant is

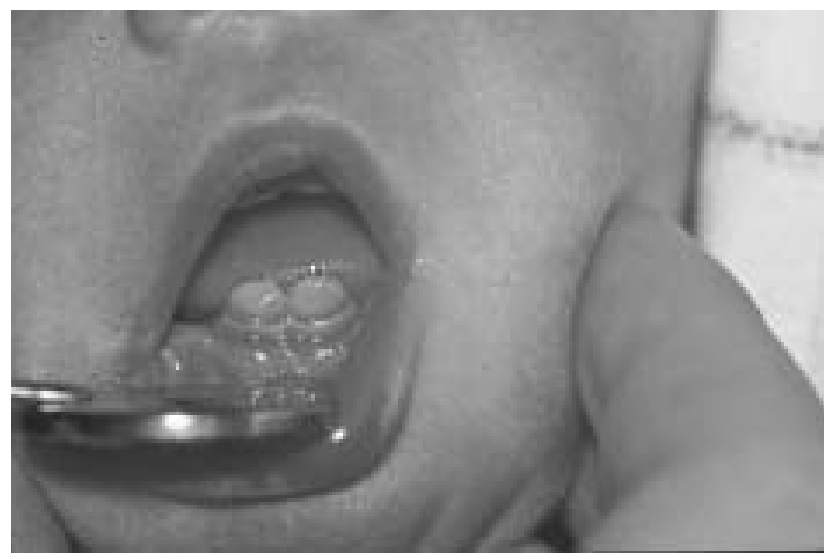

Fig. 1: 1 month old baby with natal teeth. younger than 10 days of life. For haemorrhage prevention, vitamin $\mathrm{K}$ administration is indicated (12), until the $10^{\text {th }}$ day of life when the intestinal flora becomes established and starts to produce vitamin $\mathrm{K}$. This is essential for production of prothrombin in the liver and necessary in the normal healing process $(2,43)$. If the extraction can not be delayed, consultation with the paediatrician is necessary to investigate if the child has been medicated with vitamin $\mathrm{K}$ immediately after birth as prevention of haemorrhagic disease of the newborn. Vitamin $\mathrm{K}$ is administered intramuscularly (0,5-1,0mg) (33).

Another factors to consider are implantation and degree of mobility, interferences with feeding, possibility of traumatic injury and inconveniences of sucking (35). A case was reported where the breast-feeding was prematurely interrupted due to the presence of neonatal teeth (29). If the tooth is part of normal primary dentition the maintenance of it must be the first treatment option, unless this would cause injury to the baby or to mother $(16,42)$.

One of the most common complications associated with natal and neonatal teeth is Riga-Fede Syndrome. Antonio Riga (37), Italian physician (1881), was the first who described this lesion. In 1890, F. Fede (1) published histological study of these lesions. In the late 1800s', this lesion was of particular concern in Italy because it was associated with malnourished infants and often resulted in death $(5,37)$. This syndrome refers the trauma of the tip or ventral surface of the tongue in newborn and infants (39). The lesion starts as an ulcer and after repeated trauma, progresses to an enlarged, fibrous mass, which appears like an ulcerative granuloma. Pain is present and the infant suddenly starts to suffer from dehydration, feeding difficulties and failure thrive. When the patient has systemic complications the risk of potential infection is high (46)

According to some investigators, the detection of this lesion is an indication for tooth extraction $(16,27,54)$. In some cases smoothing can relieve an acute incisal margin $(29,30)$. Goho (19) reported the treatment of a natal tooth as covering the incisal portion of the tooth with composite resin.

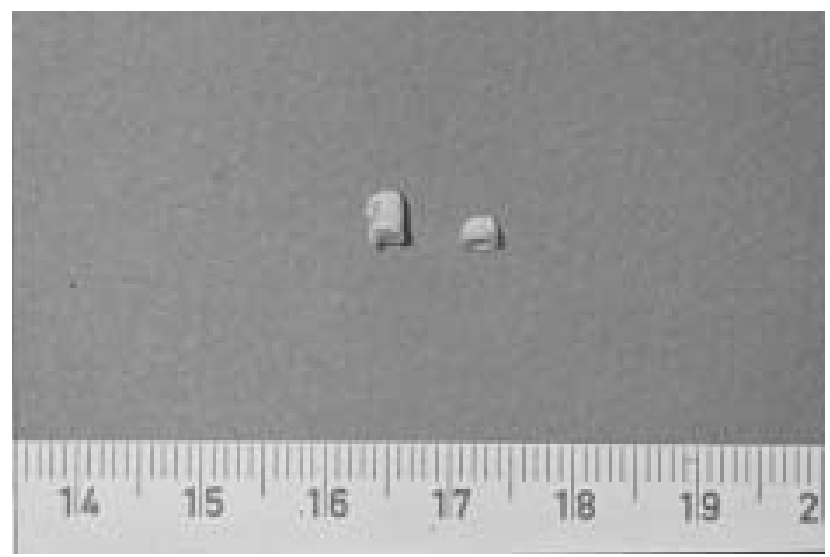

Fig. 2: Teeth after extraction. 
Baghdadi (7) published a case of Riga-Fede disease in ten-days old male infant. The incisal edge was sharp and topical triameinolone was applied, the ulcer resolved. Tomizawa (53) et al. reported seven cases of treatment of natal teeth by covering the incisal margin with resin, which aided rapid healing of the ulcers.

Stomahesive Wafers were used in some cases to cover the teeth and provide a smooth surface for the tongue to pass over during sucking, as in the cases published by Buchanan (15). He reported a case of four-week-old boy with a natal tooth and trauma of the tongue during sucking. The ulceration healed after four weeks using this conservative treatment. To relieve pain, treatment with an ointment such as Kenalog in Orabase is recommended (54).

\section{Conclusions}

Although natal and neonatal teeth do not appear frequently, proper evaluation and diagnosis are necessary for the best treatment option. Paediatricians are, usually, the first who find these teeth and early consultation with paediatric dentist can prevent complications.

Radiographic examination is the only way of revealing if the tooth is supernumerary or belongs to normal deciduous dentition. When teeth are supernumerary, they should be extracted. In this procedure, the clinician should first consider the well being of the patient and assess the risk of haemorrhage due to hypoprothrombinemia commonly present in newborns.

In most cases, natal and neonatal teeth belong to regular primary dentition and keeping these teeth in the mouth is the first choice of treatment. Alternatives such as smoothing the incisal edge or covering the edge with a composite resin are also recommended.

Periodic follow-up's by paediatric dentists are of fundamental importance, as are recommendations to the parents with respect to home dental hygiene and the use of fluoride.

\section{References}

1. Abramson M: Sublingual granuloma in infancy. J Pediatr 1944;24:195-8

2. Allwright WC. Natal and neonatal teeth. British Dent J 1958:105:163-72.

1. Almeida CM, Gomide MR, Nishiyama CK. Dente natal/neonatal. Odontologia Clinica 1997;7:43-5.

2. Alvarez MP, Crespi PV, Shanska AL. Natal molars in Pfieffer syndrome Type 3 : A case report. J Clinic Paediat Dent 1993;18:21-4.

3. Amberg S: Sublingual growth in infants. Am J Med Sci 1903;126:257-69.

4. Anneroth G, Issacson AI, Linge G. Clinical, histological and micro-radiographic study of natal, neonatal and pre-erupted teeth. J Dent Res 1978;86:58-64.

5. Baghdadi ZD. Riga-Fede disease: report of case and review. J Clin Pediatr Dent 2001;25(3):209-13.

6. Bhaskar SN. Distúrbios de desenvolvimento dos maxilares, da denticao e dos dentes. In Patologia Bucal. Sao Paulo: Artes Médicas; 1976:151.

7. Bigeard L, Hemmerle J, Sommermater JI. Clinical and ultrastructural study of the natal tooth:enamel and dentin assessments. J Dent Child 1996;63:23-31.

8. Bjuggren G. Premature eruption in the primary dentition- a clinical and radiographical study. Swed Dental J 1973;66:343-55.

9. Bodenhoff J. Natal and neonatal teeth. Dental Abstr 1960;5:485-88.

10. Bodenhoff J, Gorlin RJ. Natal and neonatal teeth: folklore and fact. Pediat 1963;32:1087-93.

11. Bowden PE, Haley JL, Kansky A, Rothnagel JA, Jones DO, Turner RJ. Mutation of a type II keratin gene (K6a) in pachynochia congenital. Nature Genetics 1995;10:363-5.
12. Brandt SK, Shapiro SD, Kittle PE. Immature primary molar in the newborn. Pediatr Dent 1983;5:210-13.

13. Buchanan S, Jenkins C. Riga-Fedes syndrome: Natal or neonatal teeth associated with tongue ulceration. Case report. Australian Dental Journal 1997;42(4): 225-7.

14. Chow MH. Natal and neonatal teeth. JADA 1980;100:215-6.

15. Fonseca MA, Mueller WA. Hallerman - Streiff syndrome:case report and recommendations for dental care. J Dent Child 1995;61:334-7.

16. Friend GW, Mincer HH, Carruth KR, Jones JE. Natal primary molar: case report. Pediatr Dent 1983;5:210-3

17. Goho C. Neonatal sublingual traumatic ulceration (Riga-Fede disease): report of cases. ASDC J Dent Child. 1996;63(5):362-4.

18. Gorlin RJ, Goldman HM, Thoma K. In: Patologia Oral. $4^{\text {th }}$ Ed. Barcelona: Salvatores; 1973:pp.163-6.

19. Gorlin RJ, Pinborg JJ, Cohen MM. Syndromes of the head and neck. New York:McGraw-Hill, 1976:82.

20. Hals E. Natal and neonatal teeth:Histologic investigations in two brothers. Oral Surg Oral Med Oral Pathol 1957;10:509-21.

21. Harila-Kaera V, Heikkinen T, Alvesalo L. The eruption of permanent incisors and first molars in prematurely born children. Eur J Orthod 2003;25(3):293-9.

22. Hebling J Zuanon ACC, Vianna DR. Dente Natal-A case of natal teeth. Odontol Clin 1997; 7:37-40

23. Hooley JR. The infant`s mouth. J AM Dent Assoc 1967;75:95-103.

24. Jasmin JR, Guerithault SC. A scanning electron microscopic study of the enamel of neonatal teeth. J Biol Buccale 1991;19:309-14.

25. Jasmin JR, Jonesco-Benaiche N, Muller-Giamarchi M. Natal and neonatal teeth Management. Ann Pediatr 1993;40(10):640-1.

26. Jeřábková N, Kučera J. Natální a neonatální zuby. Čs Pediat 1981;36:460-3.

27. Kates GA, Needleman HL, Holmes LB. Natal and neonatal teeth: A clinical study. J Am Dent Assoc 1984;109:441-3.

28. Kaur P, Sharminga A, Bhuller N. Conservative management of a complication of neonatal teeth: a case report. J Indian Soc Pedod Prev Dent 2003;21(1):27-9.

29. Komínek J, Toman J, Rozková E. Dětská Stomatologie. Praha: Avicenum, 1980.

30. Lautrou A. Abreg d'anatomie Dentaire. 2snd Ed., Paris: Masson, 1986:139-41.

31. Leone RC, Araujo MCK. Doenca hemorragica do recem-nascido. In: Pediatra basica. 8a Ed. Sao Paulo: Sarvier, 1994:430-1.

32. Leung AK. Natal teeth. Am J Dis Child 1986;140:249-51.

33. Magitot E. Anomalies in the eruption if the teeth in the man. $\mathrm{Br} \mathrm{J}$ Dent Sc 1983;26:640-1

34. Massler M, Savara BS. Natal and neonatal teeth. A review of twenty four cases reported in the literature. J Pediatr 1950;36:349-59.

35. Matias, SR, Correa, MSNP. Radiologia em odontologia: Peimeira infancia. In: Correa MSNP. Odontopediatria na Primeira infancia. Sao Paulo: Santos; 1998: 209-19.

36. Meryem U, Seval O, Hakan O, Hamdi C. Clinical and ultrastructural study of natal and neonatal teeth. J Clin Pediatr Dent 1999;23(3):173-7.

37. Moncrieff A. Sublingual ulcer: with special reference to Riga's disease. $\mathrm{Br}$ J Child Dis 1933;30:268-74

38. N K-Hussein. Natal and neonatal teeth. J Pedodont 1990;14:110-2.

39. Ooshima T, Mihara J, Saito T, Sobue S. Eruption of tooth-like like structure following the exfoliation of natal tooth: report of case. J Dent Child 1986;53. 275-8.

40. Roberts MW, Vann Jr, WF, Jewson, LG, Jacoway JR, Simon AR. Two natal maxillary molars. Oral Surg Oral Med Oral Pathol 1992;73:543-5.

41. Rusmah M. Natal and neonatal teeth: a clinical and histological study. J Clin Ped Dent 1991:15:251-3.

42. Ryba GE, Kramer IRM. Continued growth of human dentine papillae following removal of the crown of partly formed deciduous teeth. Oral Surg Oral Med Oral Pathol 1962;15:867-75.

43. Shafer WG, Hine MK, Levy BM. A Textbook of Oral Pathology. 4th ed. Philadelphia, Pa: Saunders, 1983

44. Slayton R. Treatment alternatives for sublingual traumatic ulceration (Riga-Fede disease). Pediatr Dent 2000;22:5.

45. Soni NN, Silberkweit M, Brown CH. Polarized light and microradiographic study of natal teeth. J Dent Child 1967;34:433-7.

46. Southam JC. Retained dentine papillae in the newborn: a clinical and histopatological study. Brit Dent J 1968;125:534-9.

47. Spouge JD, Feasby WH. Erupted teeth in the newborn. Oral Surg Oral Med Oral Pathol 1966;22:198-208.

48. Stewart RE, Prescott GH. Oral-facial genetics. St. Louis, CV Mosby, 1976:142.

49. Stoll C, Labay F, Geisert J, Alembik Y. Widemann-Rautenstrauch syndrome: a case report and review of the literature. Genetic Counselling 1998:9:119-24.

50. Tay WM. Natal canine and molar in an infant. Oral Surg Oral Med Oral Pathol 1970;29:598-602

51. Tomizawa M, Yamada Y, Tonouchi K, Watanabe H, Noda T. Treatment of RigaFede' $s$ disease by resin-coverage of the incisal edges and seven cases of natal and neonatal teeth. Shoni Shikagaku Zasshi. 1982;27(1):182-90.

52. Uzamis M, Turgut M, Olmez S. Neonatal sublingual traumatic ulceration (RigaFede disease): a case report. Turk J Pediatr. 1999;41(1):113-6. 
53. Walter LRF, Ferelle A, Issao M. Necessidades odontológicas congenitas e de desenvolvimento. In: Odontologia Para o Bebe. Sao Paulo: Artes Médicas; 1996:145-51.

Submitted December 2003.

Accepted June 2004.

Ana Lucía Seminario Antúnez de Mayolo, DDS, MDS,

University Hospital in Hradec Králové,

Department of Dentistry,

50005 Hradec Králové,

Czech Republic.

e-mail: anase@hotmail.com 